\title{
Reference values for lung function tests. II. Maximal respiratory pressures and voluntary ventilation
}

J.A. Neder ${ }^{1}$, S. Andreoni', M.C. Lerario ${ }^{2}$ and L.E. Nery ${ }^{3}$

\section{Correspondence \\ L.E. Nery \\ Disciplina de Pneumologia \\ EPM, UNIFESP \\ Rua Botucatu, 740, 3ำ andar \\ 04023-062 São Paulo, SP \\ Brasil \\ Fax: + 55-11-570-2127 \\ E-mail: lenery@pneumo.epm.br \\ Research partially supported by CNPq and FAPESP. J.A. Neder was \\ the recipient of a post-doctoral fellowship from FAPESP \\ (No. 95/9843-0).}

Received April 23, 1998

Accepted January 13, 1999

\author{
1Department of Physiology, St. George's Hospital M edical School, \\ University of London, London, UK \\ 2Departamento de Medicina Preventiva e Social and \\ ${ }^{3}$ Disciplina de Pneumologia, Departamento de Medicina, \\ Escola Paulista de Medicina, Universidade Federal de São Paulo, \\ São Paulo SP, Brasil
}

\section{Abstract}

The strength of the respiratory muscles can be evaluated from static measurements (maximal inspiratory and expiratory pressures, MIP and MEP) or inferred from dynamic maneuvers (maximal voluntary ventilation, MVV). Although these data could be suitable for a number of clinical and research applications, no previous studies have provided reference values for such tests using a healthy, randomly selected sample of the adult Brazilian population. With this main purpose, we prospectively evaluated 100 non-smoking subjects (50 males and 50 females), 20 to 80 years old, selected from more than 8,000 individuals. Gender-specific linear prediction equations for MIP, MEP and MVV were developed by multiple regression analysis: age and, secondarily, anthropometric measurements explained up to $56 \%$ of the variability of the dependent variables. The most cited previous studies using either Caucasian or non-Caucasian samples systematically underestimated the observed values of MIP $(\mathrm{P}<0.05)$. Interestingly, the self-reported level of regular physical activity and maximum aerobic power correlates strongly with both respiratory and peripheral muscular strength (knee extensor peak torque) $(\mathrm{P}<0.01)$. Our results, therefore, provide a new frame of reference to evaluate the normalcy of some useful indexes of respiratory muscle strength in Brazilian males and females aged 20 to 80 .

\section{Introduction}

Ventilation plays a key role in the adequacy of the external gas exchange, the ultimate lung function. The appropriateness of the "ventilatory pump" response to a given metabolic load, however, is intrinsically linked to the ability of the force-generator units (i.e., the respiratory muscles, RM) to provide the required output. RM strength can

\section{Key words}

- Respiratory muscle strength

- Maximal voluntary

ventilation

- Pulmonary function tests 
MVV is the largest volume that can be ventilated during a 10- to 15 -s interval with voluntary effort (1).

These relatively simple and inexpensive measurements, apart from having a role in the diagnosis and prognosis of a number of neuromuscular and pulmonary disorders, have been associated with health status, physical fitness and even post-surgical and general morbidity-mortality (1-3). Reference values from these important measures, as for most biological variables, should ideally derive from a randomly selected, geographically related population in an attempt to improve both accuracy and predictive power. Without this, the interpretation of the test results could be hampered and prone to misinterpretation (4). To the best of our knowledge, however, there is no published source of reference values for such variables which have been obtained from a sample of the general population of Brazil. Therefore, the purpose of this prospective study was to establish a set of predictive equations for MIP, MEP and MVV for a randomized sample of urban adult Brazilians. In addition to the typical demographic and anthropometric variables, this study evaluated the relationship of physical fitness (aerobic power and the level of regular physical activity) with these indexes of respiratory muscle strength.

\section{Material and Methods}

\section{Study design and subjects}

The exclusion criteria and the ethnic, demographic, anthropometric, spirometric and regular physical activity profile of the population evaluated was previously described in detail (5).

\section{Protocol}

The subjects were submitted to the designed protocol in the morning of the same day, and at least $3 \mathrm{~h}$ after the last meal and 12 $\mathrm{h}$ after significant exertion, following this sequence: a) complete clinical, hematologic and cardiorespiratory evaluation at rest; $b$ ) evaluation of the regular physical activity pattern by a questionnaire (6); c) determination of MIP and MEP and MVV; d) spirometry and static lung volume measurements; e) determination of the lung diffusion capacity for carbon monoxide (see Ref. 7), and f) cardiopulmonary exercise tests on a cycle ergometer (a square-wave protocol at $25 \mathrm{~W}$ for subject familiarization and, after $1 \mathrm{~h}$, a maximal ramp-incremental exercise test). On a different day, g) total and regional body composition was evaluated by dual energy X-ray absorptiometry (DEXA) and h) knee strength measured by isokinetic dynamometry. A detailed description of the techniques cited in items a, b, d, f, $g$ and $h$ was previously given (5).

Before the tests, the procedures, including the known risks, were described in detail, and written informed consent (as approved by the Institutional Medical Ethics Committee) was obtained from all subjects. The subjects did not receive remuneration.

\section{Maximal voluntary ventilation}

MVV is the largest volume that can be breathed into and out of the lungs during a 10-15-s interval with maximal voluntary effort. In this study, the subjects wore nose clips and breathed deeply (with a volume greater than the tidal volume but lower than the vital capacity) and rapidly for a 15 -s interval with flow measured by a Fleisch No. 3 pneumotachograph. After discarding the first three to five breaths, the subjects were actively encouraged to maintain the same volume and frequency by following an online display of the maneuver on a computer screen, i.e., the end-expiratory level remained relatively constant (1). At least two acceptable maneuvers (with no more than a $10 \%$ difference between them) were obtained and, 
after flow integration, the highest value was recorded by extrapolating the 15 -s accumulated volume to $1-\mathrm{min}(1 / \mathrm{min}$, body temperature, ambient pressure, saturated with water vapor - BTPS).

\section{Maximal respiratory pressures}

Maximal inspiratory pressure followed by maximal expiratory pressure was obtained from residual volume and total lung capacity, with the subjects seated wearing nose clips and with a rigid, plastic flanged mouthpiece in place. The subjects were connected to a manual shutter apparatus with the maximal pressures measured using a manometer, aneroid-type gauge $\left( \pm 300 \quad \mathrm{cmH}_{2} \mathrm{O}\right)$ (Imebrás ${ }^{\mathrm{TM}}$, São Paulo, SP, Brazil). The transducer output was regularly compared with that from the Valydine MP45-1 pressure transducer using the mechanical recording system of a Beckman R-414 polygraph. A small leak was introduced between the occlusion and the mouth in order to prevent glottic closure and in addition the subjects held their cheeks with one hand during the maneuver. Inspiratory or expiratory effort was sustained for at least $1 \mathrm{~s}$. The measurements were made by two designated technicians who always first explained and dem- onstrated the correct maneuver. The subjects performed three to five acceptable and reproducible maximal maneuvers (i.e., differences of $10 \%$ or less between values): the recorded value was the highest unless this was obtained from the last effort $(1,2,4)$. An interval of about $1 \mathrm{~min}$ was allowed to elapse between efforts.

\section{Data analysis}

The statistical approach used for data analysis (8-10) was also previously described in detail (5).

\section{Results}

Descriptive statistics of the data are shown in Table 1: age-matched males presented higher values than females for all of the variables studied and a significantly negative effect of age was found $(\mathrm{P}<0.05)$ (Figure 1). On the other hand, height, weight, lean body mass and regular level of physical activity showed a significant positive relationship (Table 2). When these variables were considered in a multiple regression analysis, only gender and age continued to have an independent predictive role for the three dependent variables (Table 3 ). In addition, in

Table 1 - Maximal respiratory pressures and voluntary ventilation in males and females by age group.

MIP = Maximal inspiratory pressure; $\mathrm{MEP}=$ maximal expiratory pressure; $\mathrm{MW}=$ maximal voluntary ventilation. Data are reported as mean \pm SD. +Significant effect among age groups within sex ( $P<0.05$ ); 20-29 age group vs 40-49, 60-69 and 70-80 groups. *Significant effect between sex groups $(P<0.05)$; males vs females by age-group.

\begin{tabular}{|c|c|c|c|c|c|c|}
\hline \multirow[t]{2}{*}{ Age (years) } & \multicolumn{3}{|c|}{ Males $(N=50)$} & \multicolumn{3}{|c|}{ Females $(\mathrm{N}=50)$} \\
\hline & $\begin{array}{c}\text { MIP } \\
\left(\mathrm{cmH}_{2} \mathrm{O}\right)\end{array}$ & $\begin{array}{c}\text { MEP } \\
\left(\mathrm{cmH}_{2} \mathrm{O}\right)\end{array}$ & $\begin{array}{l}\text { MW } \\
\text { (I) }\end{array}$ & $\begin{array}{c}\text { MIP } \\
\left(\mathrm{cmH}_{2} \mathrm{O}\right)\end{array}$ & $\begin{array}{c}\text { MEP } \\
\left(\mathrm{cmH}_{2} \mathrm{O}\right)\end{array}$ & $\begin{array}{l}\text { MW } \\
\text { (I) }\end{array}$ \\
\hline $20-29$ & $129.3 \pm 17.6^{+*}$ & $147.3 \pm 11.0^{+*}$ & $166.9 \pm 20.2^{+*}$ & $101.6 \pm 13.1^{+}$ & $114.1 \pm 14.8^{+}$ & $125.5 \pm 13.3^{+}$ \\
\hline $30-39$ & $136.1 \pm 22.0^{*}$ & $140.3 \pm 21.7^{*}$ & $170.2 \pm 29.7^{*}$ & $91.5 \pm 10.1$ & $100.6 \pm 12.1$ & $123.6 \pm 11.2$ \\
\hline $40-49$ & $115.8 \pm 87.0^{*}$ & $126.3 \pm 18.0^{*}$ & $151.2 \pm 34.4^{*}$ & $87.0 \pm 9.1$ & $85.4 \pm 13.6$ & $115.5 \pm 8.4$ \\
\hline $50-59$ & $118.1 \pm 17.6^{*}$ & $114.7 \pm 6.9^{*}$ & $132.4 \pm 27.4^{*}$ & $79.3 \pm 9.5$ & $83.0 \pm 6.2$ & $105.9 \pm 20.8$ \\
\hline $60-69$ & $100.0 \pm 10.6^{*}$ & $111.2 \pm 10.9^{*}$ & $138.8 \pm 22.0^{*}$ & $85.3 \pm 5.5$ & $75.6 \pm 10.7$ & $95.7 \pm 19.3$ \\
\hline $70-80$ & $92.8 \pm 72.8^{*}$ & $111.5 \pm 21.0^{*}$ & $108.0 \pm 25.6$ & $72.7 \pm 3.9$ & $69.6 \pm 6.7$ & $93.5 \pm 18.9$ \\
\hline
\end{tabular}


A

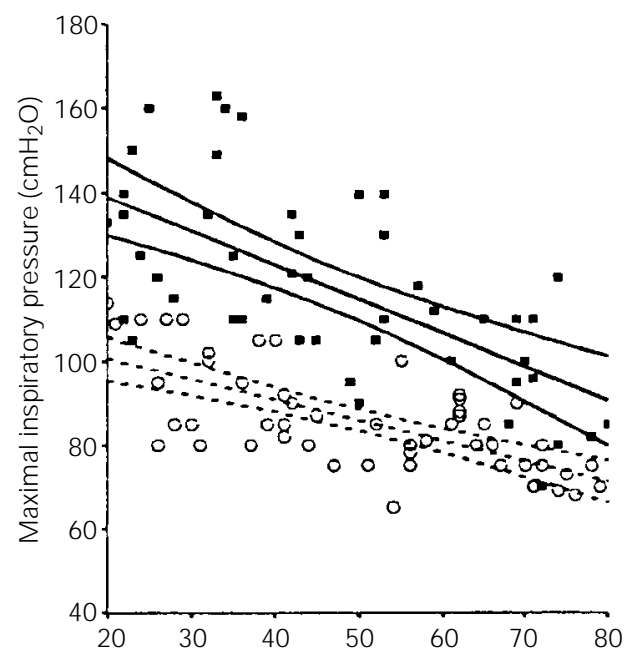

B
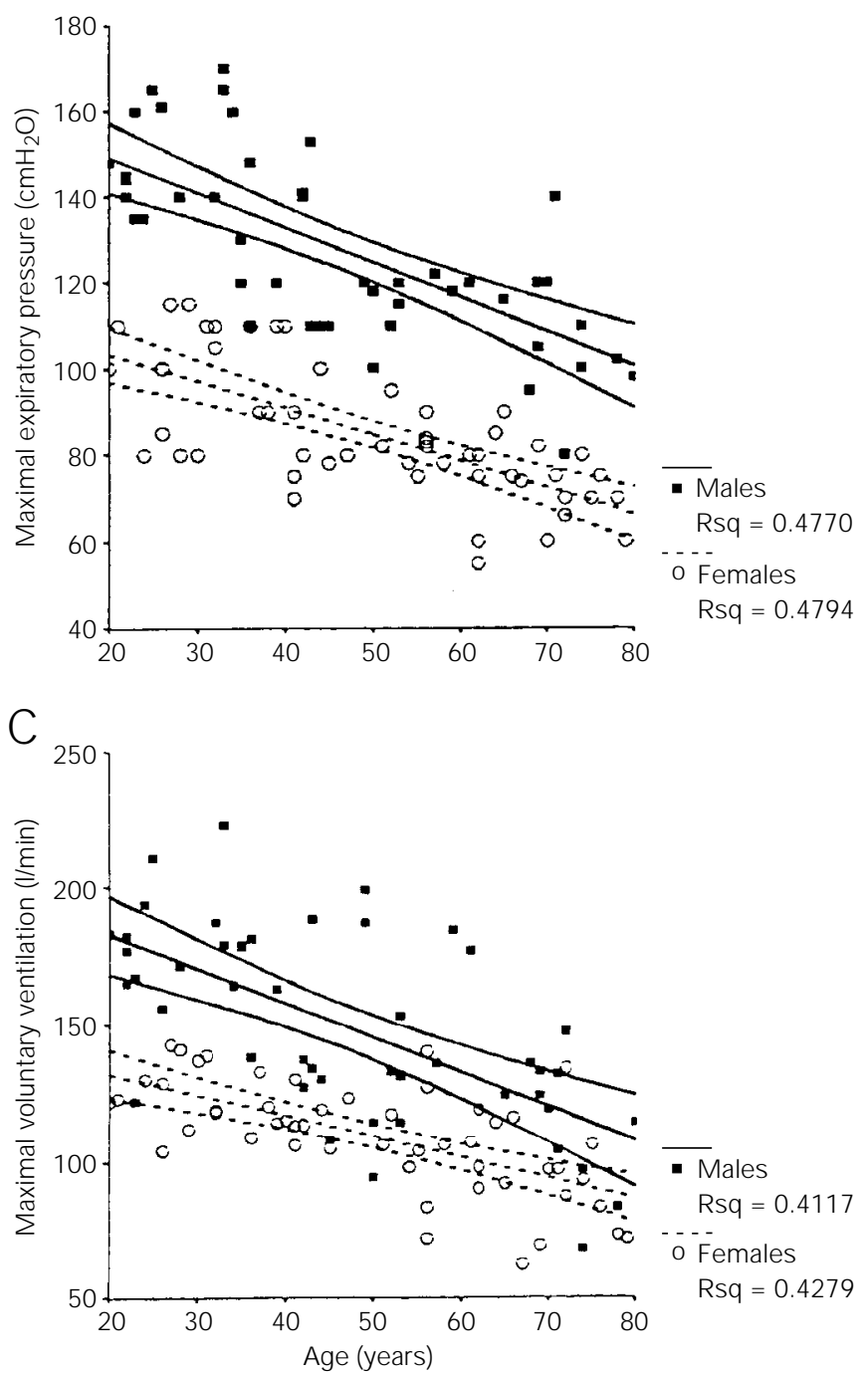

Figure 1 - Maximal inspiratory pressure (MIP) (A), expiratory pressure (MEP) (B) and voluntary ventilation (MW) (C) as a function of age in 100 healthy sedentary subjects. Regression lines are presented with the corresponding $95 \%$ confidence limits (CL).

MIP: Males: $y=-0.80$ (age) +155.3 , SEE $=17.3$; Females: $y=-0.49$ (age) +110.4 , SEE $=9.1$.

MEP: Males: $y=-0.81$ (age) +165.3 , SEE $=15.6$; Females: $y=-0.61$ (age) +115.6, SEE $=11.2$.

MW: Males: $y=-1.12$ (age) $+199.1, \mathrm{SEE}=27.5$; Females: $y=-0.76$ (age) +147.4 , SEE $=15.3$.

All regressions were statistically significant at $P<0.01$. Rsq is the coefficient of determination.

\begin{tabular}{l} 
- Males \\
$\quad$ Rsq $=0.4244$ \\
\hdashline- Females \\
$\quad$ Rsq $=0.4646$
\end{tabular}

the male group, weight was also a predictor of MIP and height of MVV. The other more complex measurements did not continue to show independent predictive power for MIP, MEP and MVV when these simpler variables were considered in the multiple regression (Table 3).

Direct comparison of equations from the most cited previous studies using both Caucasian (11-13) and non-Caucasian samples (14) showed that they systematically underestimated the observed values of MIP in both sexes $(\mathrm{P}<0.05$; Figure 2$)$. Additionally, after application of the predicted residual sum of squares (PRESS) method to the linear regression equations, we found only a mild effect in the $\mathrm{R}$ and standard error of the estimate (SEE) original values (RPRESS ranging from $0.018-0.038$ units below original $R$ and SEEPRESS values being 3-6\% higher than the original SEE values (data not shown).

Interestingly, we found a significant positive linear association between both peripheral (knee extensor peak torque) and respiratory muscle strength (MIP, MEP, MVV) and the physical activity score, independent of gender or age (Figure 3 ). In addition, a similar result was obtained with regard to the peak aerobic power - $\dot{\mathrm{V}} \mathrm{O}_{2} \max$ (Table 2).

As previously reported (15), MVV was closely related to forced expiratory volume in $1 \mathrm{~s}\left(\mathrm{FEV}_{1}\right)$ in an effectively linear fashion with a positive intercept $\left(\mathrm{R}^{2}=0.817\right)$, although we found a different slope value 

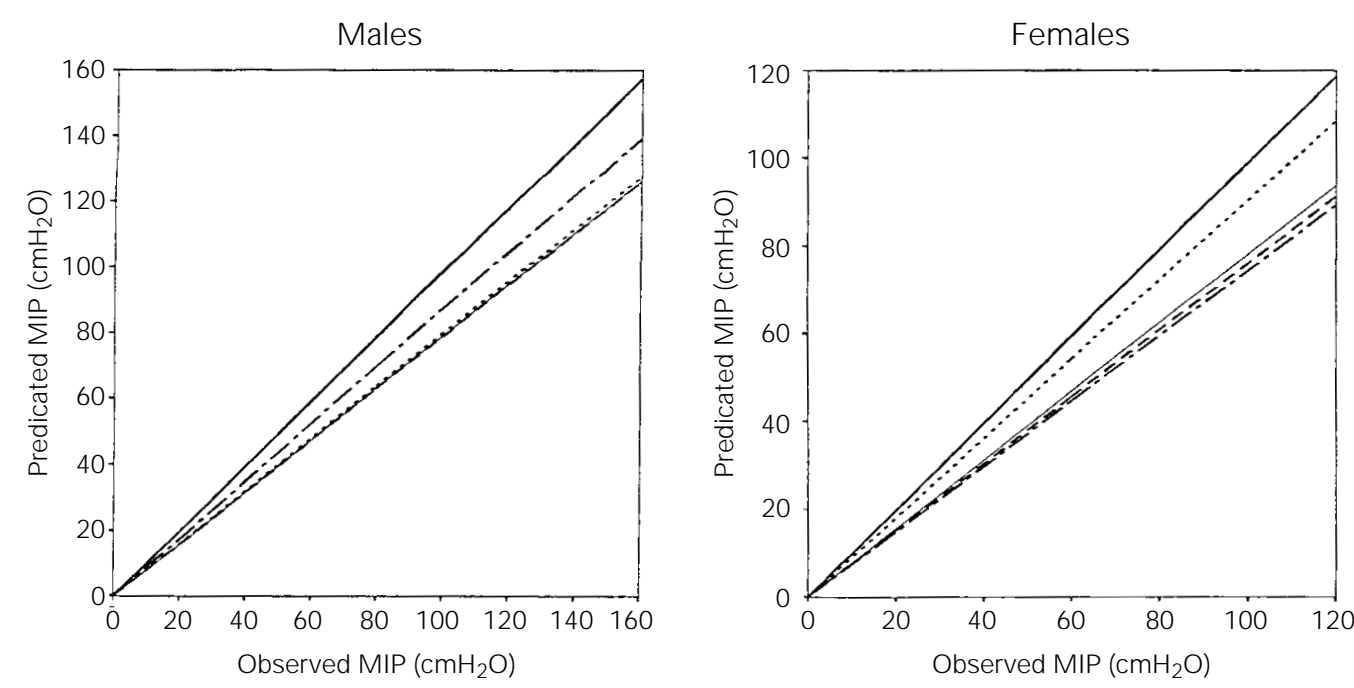

Figure 2 - Observed and predicted values of maximal inspiratory pressure (MIP) reported in the present study and in the most cited previous studies (1114). Note that these studies underestimated the observed values in both males and females $(\mathrm{P}<0.05)$.

Wilson et al. (12) - - —Enright et al. (13) ..... - Blackie and Hyatt (11) - -- J ohan et al. (14) —— Present study

Table 2 - Correlation matrix.

LBM = Lean body mass; $\mathrm{PAS}=$ physical activity score; $\dot{\mathrm{V}}_{2} \mathrm{max}=$ maximum oxygen uptake; $\mathrm{MIP}=$ maximal inspiratory pressure; $\mathrm{MEP}=$ maximal expiratory pressure; $\mathrm{MWV}=$ maximal voluntary ventilation. ${ }^{*} \mathrm{P}<0.05$. ${ }^{* *} \mathrm{P}<0.01$.

\begin{tabular}{|c|c|c|c|c|c|c|c|c|c|c|}
\hline & Age & Height & Weight & LBM & PAS & $\dot{\mathrm{V}} \mathrm{O}_{2} \max$ & Leg strength & MIP & MEP & $\mathrm{MW}$ \\
\hline Age & 1.00 & & & & & & & & & \\
\hline Height & $-0.22^{*}$ & 1.00 & & & & & & & & \\
\hline Weight & -0.01 & $0.54 * *$ & 1.00 & & & & & & & \\
\hline LBM & $-0.24 *$ & $0.79 * *$ & $0.84^{* *}$ & 1.00 & & & & & & \\
\hline PAS & $-0.28 * *$ & $0.38 * *$ & $0.23^{*}$ & $0.42 * *$ & 1.00 & & & & & \\
\hline$\dot{\mathrm{V}} \mathrm{O}_{2} \max$ & $-0.61 * *$ & $0.67^{* *}$ & $0.50 * *$ & $0.77^{* *}$ & $0.58 * *$ & 1.00 & & & & \\
\hline Leg strength & $-0.71 * *$ & $0.71 * *$ & $0.46 * *$ & $0.79 * *$ & $0.47 * *$ & $0.86 * *$ & 1.00 & & & \\
\hline MIP & $-0.54 * *$ & $0.49 * *$ & $0.36 * *$ & $0.66^{* *}$ & $0.47^{* *}$ & $0.81^{* *}$ & $0.76^{* *}$ & 1.00 & & \\
\hline MEP & $-0.51 * *$ & $0.59 * *$ & $0.49 * *$ & $0.70 * *$ & $0.46^{* *}$ & $0.85^{* *}$ & $0.79 * *$ & $0.85^{* *}$ & 1.00 & \\
\hline MWV & $-0.56 * *$ & $0.63^{* *}$ & $0.38 * *$ & $0.67 * *$ & $0.48^{* *}$ & $0.81^{* *}$ & $0.81^{* *}$ & $0.67 * *$ & $0.72^{* *}$ & 1.00 \\
\hline
\end{tabular}

Table 3 - Linear prediction equations for maximal inspiratory pressure (MIP), expiratory pressure (MEP) and voluntary ventilation (MV) in males (M) and females (F) aged 20 to 80.

Values in the columns represent coefficient estimates followed by the respective standard error of the estimate. $R^{2}=$ Coefficient of determination; RSE = residual standard error.

\begin{tabular}{lcccccrr}
\hline Variable & Sex & Age (years) & Height $(\mathrm{cm})$ & Weight $(\mathrm{kg})$ & Constant & $\mathrm{R}^{2}$ & RSE \\
\hline MIP $\left(\mathrm{cmH}_{2} \mathrm{O}\right)$ & $\mathrm{M}$ & $-0.80 \pm 0.13$ & - & $0.48 \pm 0.22$ & $119.7 \pm 17.9$ & 0.479 & 16.7 \\
& $\mathrm{~F}$ & $-0.49 \pm 0.07$ & - & - & $110.5 \pm 3.9$ & 0.465 & 9.1 \\
$\mathrm{MEP}\left(\mathrm{cmH}_{2} \mathrm{O}\right)$ & $\mathrm{M}$ & $-0.81 \pm 0.12$ & - & - & $165.3 \pm 6.3$ & 0.477 & 15.6 \\
& $\mathrm{~F}$ & $-0.62 \pm 0.09$ & - & - & $115.7 \pm 4.8$ & 0.479 & 11.2 \\
$\mathrm{MW}(\mathrm{I} / \mathrm{min})$ & $\mathrm{M}$ & $-1.06 \pm 0.19$ & $2.15 \pm 0.53$ & - & $-164.6 \pm 93.3$ & 0.567 & 23.7 \\
& $\mathrm{~F}$ & $-0.76 \pm 0.12$ & - & - & $47.4 \pm 6.6$ & 0.428 & 15.3
\end{tabular}


(37.5) than previously described (Figure 4). Finally, the minute ventilation at maximal cycle ergometry (VEmax) was lower than the MVV in all subjects, and these values were higher in males independent of age: the gender-specific upper $95 \%$ confidence interval of the predicted values for the VEmax/ MVV ratio was, therefore, at variance with

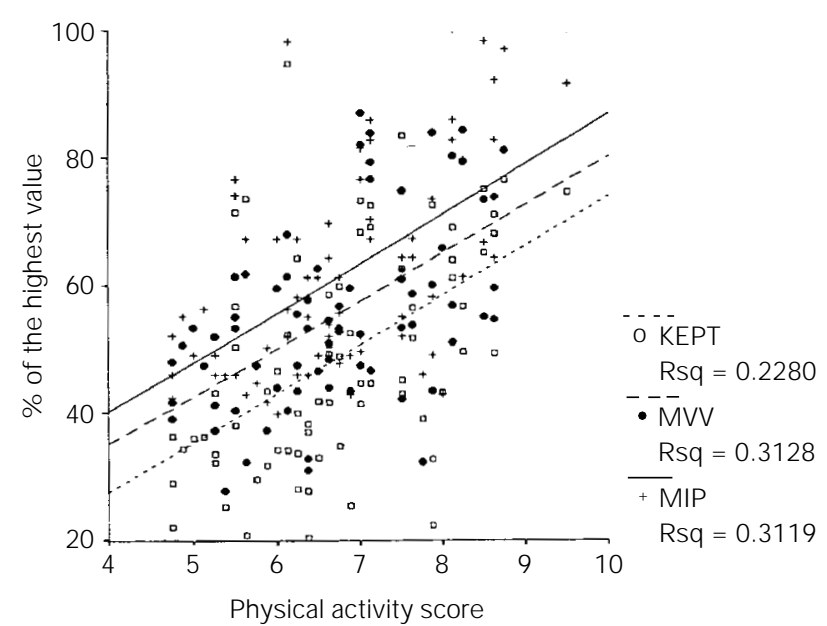

Figure 3 - Positive correlation between physical activity score (6) and some indexes of muscular strength such as peripheral (knee extensor peak torque, KEPT) and respiratory (maximal voluntary ventilation, MW and maximal inspiratory pressure, MIP) strength. $\mathrm{P}<0.001$ for all correlations.

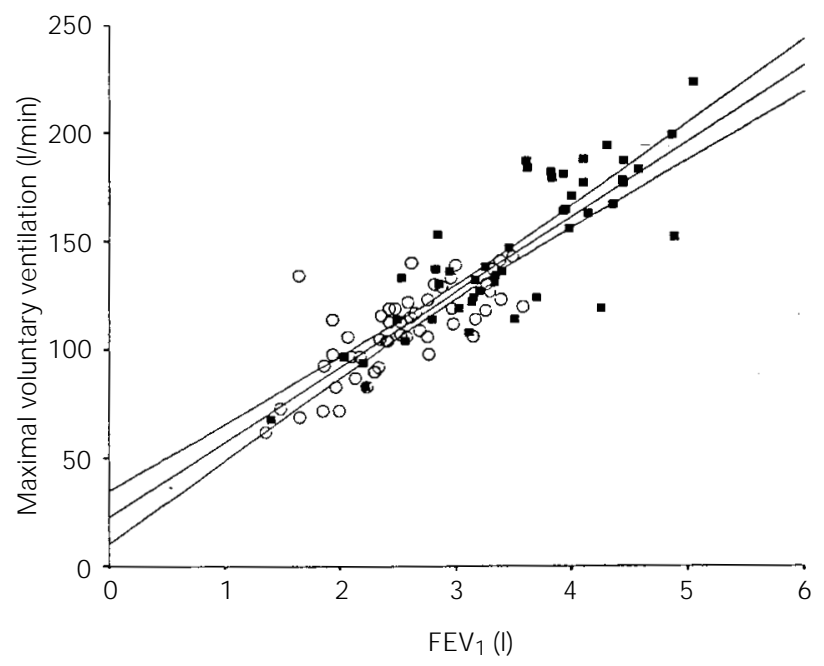

Figure 4 - Maximal voluntary ventilation (MV) was closely correlated with the forced expiratory volume in $1 \mathrm{~s}\left(\mathrm{FEV}_{1}\right)$ but with a positive $y$ intercept: $\mathrm{MW}(\mathrm{I} / \mathrm{min})=37.5\left(\mathrm{FEV}_{1}\right)+15.8, \mathrm{R}^{2}=0.817, \mathrm{SEE}=15$. the previously suggested single cutoff $(0.80)$ (16), i.e., 0.87 for males and 0.77 for females (Figure 5).

\section{Discussion}

This study is the second communication in a sequence of descriptions of reference values for lung function tests (other than spirometry) which were obtained in a carefully randomly selected sample (5). This experiment provides the first set of predictive equations for some clinically useful indexes of muscular respiratory strength obtained for a randomly selected sample of healthy adult Brazilians. We found that age and, secondarily, anthropometric measurements were able to explain up to $56 \%$ of the variability of the dependent variables. Interestingly, previous studies using either Caucasian or non-Caucasian samples underestimated the observed values of MIP $(\mathrm{P}<0.05)$, the most used index of maximal respiratory strength (1-3). These results demonstrate the practical importance of considering reference values for lung function tests which are obtained from a racially, ethnically and geographically related population (4).

Age was the strongest negative correlate with the studied dependent variables (Table 2 , Figure 1). The aging process is associated with a reduction in the total, diaphragmatic and respiratory accessory muscular mass, as well as with a decline in the work output for a same level of neural stimulation (13). Increased compliance of the abdominal compartment in older subjects can dissipate the generated pressure, notably in the forced expiration, reducing the maximal static pressures. Additionally, as we demonstrated previously in this sample, there is a mild reduction in the total lung capacity and a marked increase in residual volume with age. Considering that the highest values for MIP and MEP are generated in the lowest and the highest lung volumes, respectively, these physiological adaptations may also contri- 
bute to the age-associated decline in MIP and MEP. On the other hand, weight was a positive predictor of MIP but only in males (Table 3). This finding may be anticipated considering the closer relationship between total and lean body mass (LBM) in males than in females, and the stronger relationship between MIP and LBM (Table 2).

The MVV is a test of the overall function of the respiratory system. It is influenced not only by RM strength, but also by the compliance of the lung-thorax system, the condition of the ventilatory control systems and the resistance of both airways and tissues. Apart from the reduction in RM strength (Figure 1, Tables 1 to 3), aging is associated with reductions in the compliance of the chest wall and an increase in both the resistive and elastic work of breathing (13). It is important, therefore, to recognize that MVV was used in this study only as an indirect index of RM strength and these other factors should also be considered in the analysis of the results. In addition, we obtained two original results with practical implications: i) the indirect estimation of MVV from $\mathrm{FEV}_{1}$ (x 37.5) should include a positive intercept (15 1) (Figure 4), and ii) the widely used single cutoff employed to suggest ventilatory limitation to dynamic exercise (VEmax/ MVV ratio above 0.8 ) should also take gender into account ( $95 \%$ upper confidence limit of 0.87 for males and 0.77 for females; Figure 5). Obviously, these findings have important implications for the exercise-based diagnostic process.

One of the most remarkable findings of the present study was the degree of underestimation of the observed MIP values by previously published equations for a sample with a minority of Caucasian subjects (1114). This finding was unexpected due to the traditional notion that non-white, non-Caucasian populations present lower values for most tests of the different aspects of lung function (4). A biased selection in the present population can be ruled out by the care- ful randomization procedure applied and, in addition, this sample was highly unfit and sedentary. Ethnic aspects based on differences in sitting height, arm span, chest wall geometry or degree of muscularity of the primary and secondary respiratory muscles could be considered, but unfortunately we are not aware of any systematic comparison among these variables in different ethnic groups and races. Another important aspect that impairs any direct comparison among studies is the relative non-standardization of these highly effort-dependent tests. Previous investigators used different techniques, particularly the type of mouthpiece used. We used a flanged mouthpiece, which is more commonly used in pulmonary function laboratories, but this is unlikely to contribute to the discrepancy since lower values were observed with the use of this kind of mouthpiece compared to a rubber tube (17). In addition, as cited in Methods, systematic measurement errors are also unlikely since the output of the device was regularly checked against a highly sensitive differential pressure transducer. Another reasonable hypothesis to account for these discrepancies could

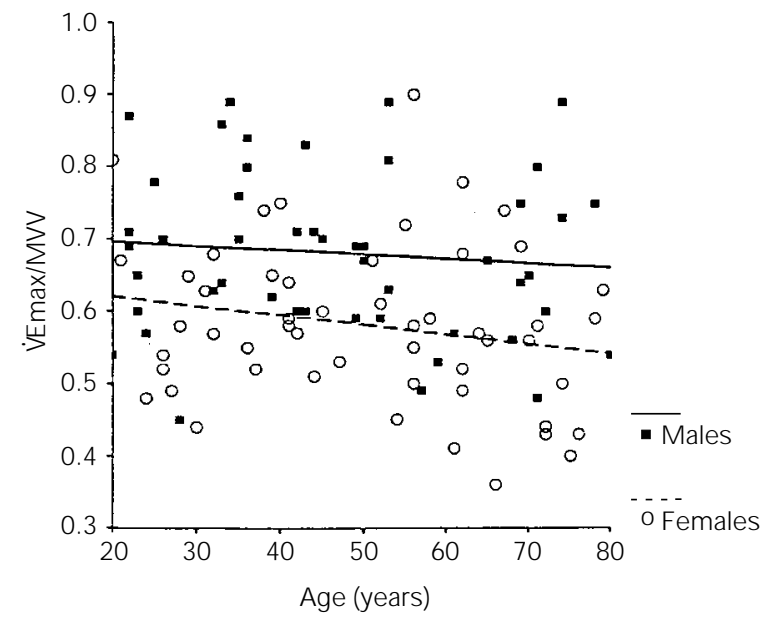

Figure 5 - The ventilatory stress at maximum cycle ergometry (VEmax/MV ratio) was lower than one in all subjects, independent of gender. Males showed higher values than females (with an upper $95 \%$ confidence limit of 0.87 and 0.77 , respectively), but no effect of age was found $(P<0.05)$ 
be a lower end-expiratory level attained by our subjects prior to the inspiration. In the previous communication (5), however, we were not able to find a systematic low value of residual volume or end-expiratory lung volume in either sex. On the other hand, in a non-randomized study involving a smaller Brazilian sample $(30 \mathrm{M} / 30 \mathrm{~F}$, aged below 50 years), Camelo Jr et al. (18), using a similar device, described higher values for MIP in males and MEP in both sexes as compared to our study. Whether these discrepancies could be associated with the non-randomized design of the previous evaluation and/or differences in muscularity is presently unknown: unfortunately, a direct comparison between studies was not feasible since these authors did not develop regression equations. Further work, therefore, is required to evaluate specifically the possible determinants of this rather unexpected finding of the present study.

Another interesting finding was the significant linear relationship between peripheral or respiratory muscle strength and the regular level of physical activity and $\mathrm{VO}_{2}$ max (Table 2, Figure 3). This occurred even though all of the studied subjects were considered to be untrained (6); however, as expected, we found a considerable range of values in the regular physical activity scores (Figure 3). There was, undoubtedly, a high level of multi-colinearity in the above-mentioned analysis. The fact that the younger, taller, leaner and more active males presented also higher values of muscular strength does not necessarily represent a cause-effect relationship. However, there is now growing evidence that whole-body dynamic exercise training is associated with an increase in both peripheral and respiratory muscle strength and endurance capacity $(19,20)$.
Therefore, we could not entirely rule out the hypothesis that this result reflects the beneficial effect of regular physical activity on ventilatory pump performance.

In summary, we have presented the first set of predictive equations for static respiratory pressures (MIP and MEP) and MVV in a randomized sample of adult Brazilians. Our results can be applied in clinical and research situations to evaluate the adequacy of these useful indexes of respiratory muscle strength in males and females aged 20 to 80 . These equations, however, should be validated further in other samples of the adult Brazilian population.

\section{Acknowledgments}

The authors thank Prof. Dr. Adauto Castelo Filho, Clovis Peres, and Antonio C. Silva (EPM, UNIFESP) for helpful comments; Luíza Hashimoto, Maura Hashimoto, Daniel Siquieroli, Márcio Tonini and Vera Rigoni from the Pulmonary Function and Exercise Laboratories of the Pulmonary Division (EPM, UNIFESP) for skilled technical assistance; Marcello DiPietro for his excellent work in preparing the data storage software system (CPX Data); the technical staff of the LAFIREX - Exercise Laboratory of the Department of Physiology (EPM, UNIFESP) for performing the isokinetic dynamometry; the Endocrinology Division of EPM, UNIFESP for providing the DEXA system, and principally all of the participants for their efforts and cooperation. Additionally, the authors are indebted to Mrs. Pat Chapman (Department of Physiology, St. George's Hospital Medical School, London) for competently revising the English language. 


\section{References}

1. Ruppel G (1994). Lung volume tests. In: Ruppel G (Editor), Manual of Pulmonary Function Testing. 6th edn. Mosby, St. Louis, 1-25.

2. Celli BR (1989). Clinical and physiological evaluation of respiratory muscle function. Clinics in Chest Medicine, 10: 199-214.

3. Arora NS \& Rochester DF (1982). Respiratory muscle strength and maximal voluntary ventilation in undernourished patients. American Review of Respiratory Diseases, 126: 5-8.

4. American Thoracic Society (1991). Lung function testing. Selection of reference values and interpretative strategies. American Review of Respiratory Diseases, 144: 1202-1218.

5. Neder J A, Andreoni S, Castelo-Filho A \& Nery LE (1999). Reference values for lung function tests. I. Static volumes. Brazilian J ournal of Medical and Biological Research, 32: 703-717.

6. Baecke JAH, Burema J \& Frijters J ER (1982). A short questionnaire for the measurement of habitual physical activity in epidemiological studies. American J ournal of Clinical Nutrition, 36: 936-942.

7. Neder J A, Andreoni S, Peres C \& Nery LE (1999). Reference values for lung function tests. III. Carbon monoxide diffusing capacity (transfer factor). Brazilian J ournal of Medical and Biological Research, 32:
729-737.

8. Statistical Package for Social Sciences (SPSS, IBM +) (1990). Version 6.20.1.

9. Kleinbaum DG, Kupper LL \& Muller AE (1988). Applied Regression Analysis and Other Multivariable Methods. 2nd edn. Duxbury Press, Belmont.

10. Holiday DB, Ballard JE \& McKeown BC (1995). PRESS-related statistics: regression tools for cross-validation and case diagnostics. Medicine and Science in Sports and Exercise, 27: 612-620.

11. Black LF \& Hyatt RE (1969). Maximal respiratory pressures: normal values and relationship to age and sex. American Review of Respiratory Diseases, 99: 696702.

12. Wilson SH, Cooke NT, Edwards RHT \& Spiro SG (1984). Predicted normal values for maximal respiratory pressures in Caucasian adults and children. Thorax, 39: 535-538.

13. Enright $\mathrm{PL}$, Kronmal R, Manollo TA, Schenker MB \& Hyatt RE (1994). Respiratory muscle strength in the elderly: correlates and reference values. American J ournal of Respiratory and Critical Care Medicine, 149: 430-438.

14. J ohan A, Chan CC, Chia HP, Chan OY \& Wang YT (1997). Maximal respiratory pressures in adult Chinese, Malays and Indians. European Respiratory J ournal, 10:
2825-2828.

15. Campbell SC (1982). A comparison of the maximum voluntary ventilation with forced expiratory volume in one second: an assessment of subject cooperation. J ournal of Occupational Medicine, 24: 531-533.

16. Hansen JE, Sue DY \& Wasserman $K$ (1984). Predicted values for clinical exercise testing. American Review of Respiratory Diseases, 129 (Suppl): S49-S55.

17. Koulouris N, Mulvey DA, Laroche CM, Green M \& Moxhan J (1988). Comparison of two different mouthpieces for the measurement of PImax and PEmax in normal and weak subjects. European Respiratory J ournal, 1: 863-867.

18. Camelo J r J S, Terra Fo J T \& Manço J C (1985). Maximal respiratory pressures in normal adults. J ornal de Pneumologia, 11: 181-184.

19. Leith DE \& Bradley M (1978). Ventilatory muscle strength and endurance training. J ournal of Applied Physiology, 41: 508516.

20. Powers SK \& Criswell D (1996). Adaptive strategies of respiratory muscles in response to endurance exercise. Medicine and Science in Sports and Exercise, 28: 1115-1122. 